\title{
O emergir da perspectiva de Ensino por Pesquisa de Núcleos Integrados no contexto da implementação de uma proposta CTSA no Ensino Médio
}

\author{
The emergence of the teaching for research perspective \\ in integrated centers in the context of the implementation \\ of a STSE proposal in High School
}

Thiago Vasconcelos Ribeiro ${ }^{1}$ • Luiz Gonzaga Roversi Genovese ${ }^{1}$

\begin{abstract}
Resumo: O presente artigo analisa uma proposta de Alfabetização Científica e Tecnológica no contexto da Educação Básica. As atividades dessa proposta foram desenvolvidas junto a alunos da $2^{\mathrm{a}}$ série do Ensino Médio de uma escola pública de Goiânia. Estas atividades buscaram articular os elementos da perspectiva de Ensino por Pesquisa. Assim, os alunos realizaram um estudo sobre aparelhos tecnológicos na abordagem CTSA. As categorias de análise construídas sinalizaram: momentos de aprendizagens relevantes, a articulação de elementos de motivação e mobilização, a construção de ambientes democráticos de participação e decisão, além do estabelecimento de momentos de discussão, nos quais alunos tiveram a oportunidade de debater e argumentar sobre diversas problemáticas presentes em seus cotidianos. As categorias de análise permitiram, ainda, repensar os elementos do referencial teórico empregado, o que resultou em um quadro teórico distinto do adotado inicialmente, que aqui é denominado Ensino por Pesquisa de Núcleos Integrados.
\end{abstract}

Palavras-chave: Ciência, Tecnologia, Sociedade e Ambiente. CTSA. Ensino por Pesquisa. Ensino Médio. Alfabetização científica e tecnológica.

\begin{abstract}
This paper analyzes a proposal for Scientific and Technological Literacy in the context of basic education. The activities of this proposal were developed among second year students of a public High School in Goiânia, Brazil. These activities sought to articulate the elements from the perspective of Teaching Trough Research. Thus, the students conducted a study about technological devices guided by a STSE approach. The categories of analysis signaled moments of relevant learning, the articulation of elements of motivation and mobilization, the build of democratic environments of participation and decision, in addition to establishing moments of discussion, in which students had the opportunity to debate and argue over various problems present in their daily lives. The categories of analysis also allowed rethink the elements of the theoretical referential employed, which resulted in a distinct theoretical framework from the adopted initially, which is here called Teaching for Research in Integrated Centers.
\end{abstract}

Keywords: Science, Technology, Society and Environment. STSE. Teaching through Research. Secondary education. Scientific and technological literacy.

\footnotetext{
${ }^{1}$ Instituto de Física, Universidade Federal de Goiás (UFG), Campus Samambaia, caixa postal 131, CEP 74001-970, Goiânia, GO, Brasil. E-mail: thiago.v.ribeiro@live.com
} 


\section{Introdução}

O mundo contemporâneo é caracterizado pela rápida produção, ampla difusão e significativa valorização do conhecimento científico. Não por acaso, as relações sociais são influenciadas direta e indiretamente pelo conhecimento proveniente da Ciência, que, quando associado à Tecnologia e aos mecanismos de produção e acumulação de capital, se torna capaz de estabelecer novos valores, hábitos, normas e princípios de convivência social (GRANGER, 1994; HABERMAS, 2011).

Desta forma, é necessário e urgente uma formação em Ciências que torne tais aspectos inteligíveis aos alunos. Portanto, o ensino de ciências deve empenhar-se na "construção de conceitos, competências, atitudes e valores” (CACHAPUZ; PRAIA; JORGE, 2002, p. 142) visando à formação de cidadãos cientificamente cultos, capazes de compreender as problemáticas intrínsecas à realidade que os cerca, bem como serem capazes de argumentar, debater e assumir um posicionamento crítico que oriente a tomada de posição perante ela (GIL-PÉREZ; VILCHES, 2011).

Para proporcionar tal aprendizagem, no seio do Ensino de Ciências, emergiu o movimento Ciência, Tecnologia e Sociedade (CTS) / Ciência, Tecnologia, Sociedade e Ambiente (CTSA) (ZIMAN, 1980), que visa promover abordagens críticas às problemáticas reais e abertas que sejam familiares ao aluno, a fim de tornar o processo de ensino e aprendizagem em ciências mais significativo e socialmente relevante (DEBOER, 1991; YAGER, 1996).

Nessa perspectiva, o ensino de ciências em CTS defende que, além de se transmitir o conhecimento científico produzido, estabelecido e legitimado, enquanto produto acabado, deve-se ensinar sobre a Ciência, portanto, abordar os processos sócio-históricos de produção, construção e legitimação dos fatos científicos, abordando as questões filosóficas, éticas e políticas pertinentes envolvidas (COLLINS; PINCH, 2010; ZIMAN, 1980). Procura-se, desta forma, caracterizar a Ciência e a Tecnologia como parte integrante da cultura ocidental contemporânea, consistindo em atividades humanas construídas socialmente (LATOUR, 2011). Logo, o ensino de ciências CTS visa desenvolver, junto aos alunos, uma percepção do desenvolvimento científico e tecnológico como um processo social, influenciado por fatores culturais, sociais, políticos e econômicos, além dos tradicionais fatores epistêmicos (BAZZO; LINSINGEN; PEREIRA, 2003).

$\mathrm{Na}$ tentativa de tornar o aprendizado de ciências mais significativo e relevante, a partir dessa caracterização das relações entre a Ciência, a Tecnologia e a Sociedade, o objetivo principal do ensino de ciências CTS é formar cidadãos aptos a tomarem decisões acerca das problemáticas científicas e tecnológicas contemporâneas (AIKENHEAD, 1992; PRAIA; CACHAPUZ, 2005; SOLOMON, 1994). Nesse sentido, pesquisas destacam a importância de se trabalharem: questões sociocientíficas na formação ética/moral dos alunos; a exploração do potencial pedagógico do discurso e da argumentação, das conexões emotivas, psicológicas, culturais e epistemológicas orientada à tomada de decisões informadas (ZEIDLER et al., 2005); a ênfase na formação para a responsabilidade social, e a construção de uma consciência coletiva organizada em ciclos de responsabilidade (WAKS, 1992, 1996); e a construção de conhecimentos interdisciplinares, socialmente relevantes, necessários ao diálogo com os especialistas da Ciência e direcionados à ação social prática e à tomada de decisões, exercitando o raciocínio crítico, a capacidade de comunicação e a busca por soluções criativas (AIKENHEAD, 1988, 1994; GORDILLO; OSORIO, 2003). 
Os pressupostos do movimento CTSA são empregados, ainda, como mecanismo para promover a alfabetização científica e tecnológica, na exata medida em que visa proporcionar, aos alunos: uma compreensão atual e mais ampla da natureza da Ciência e da Tecnologia e o seu papel na sociedade (ACEVEDO DÍAZ; VÁZQUEZ ALONSO; MANASSERO MAS, 2003); fomentar habilidades analíticas, comunicativas e de pesquisa; formar cidadãos capazes de lidarem com informações disponíveis e preparados para tratarem, com responsabilidade, os assuntos científicos em contexto social; desenvolverem autonomia de pensamento e capacidade de identificação e solução de problemas socialmente relevantes, tornando-os capazes de atuarem coletivamente, estimulando-os a tomarem decisões e a descobrirem as fronteiras entre a escola e a comunidade, tornando-as mais transparentes e permeáveis (PENICK, 1998).

Nesse contexto, o Ensino por Pesquisa proposto por Cachapuz, Praia e Jorge (2002), diferenciando-se das demais propostas de ensino de ciências por meio de atividades de investigação e pesquisa (GIL-PÉREZ; CARRASCOSA-ALIS, 1994; POZO; CRESPO, 2009), apropria-se desses elementos presentes nos estudos CTS/CTSA para a elaboração de estratégias de ensino e aprendizagem que visam a formação científica crítica e a (re)construção de conhecimentos socialmente relevantes. Logo, o presente trabalho orienta-se pelos pressupostos da perspectiva de Ensino por Pesquisa (CACHAPUZ; PRAIA; JORGE, 2002) para apresentar e discutir os resultados de uma intervenção desenvolvida em uma escola pública de Goiânia, em que os alunos participantes se envolveram em atividades didáticas de ensino por meio da pesquisa, sendo essas estratégias pautadas em pressupostos do movimento CTSA. Buscando ir mais além, as reflexões críticas aqui apresentadas possibilitaram repensar os elementos dessa perspectiva que, por sua vez, culminaram em um quadro teórico distinto do adotado inicialmente, o Ensino por Pesquisa de Núcleos Integrados.

\section{Fundamentação teórica}

O Ensino por Pesquisa (EPP), proposto por Cachapuz, Praia e Jorge (2002), enquanto perspectiva educacional, visa a "construção de conceitos, competências, atitudes e valores" (CACHAPUZ; PRAIA; JORGE, 2002, p. 142), em uma educação voltada para a formação de cidadãos cientificamente cultos. Para propiciar tais aprendizagens, o EPP é estruturado em três momentos: problematização, metodologias de trabalho e avaliação terminal da aprendizagem e do ensino (Figura 1).

No primeiro momento, denominado problematização, há três grandes polos de conhecimentos que interagem entre si. O polo Currículo intencional contém o conjunto de saberes associados às disciplinas tradicionalmente estabelecidas, além de outros tipos de saberes, tais como saberes de ordem e relevância social, humana e ambiental, considerados igualmente importantes para o cultivo e desenvolvimento de capacidades, valores e atitudes, imprescindíveis para a formação dos alunos. O polo Saberes acadêmicos, pessoais e sociais dos alunos está relacionado com uma série de conhecimentos que os alunos trazem consigo, sejam eles provenientes de seu cotidiano ou adquiridos durante sua trajetória escolar. O polo Situaçôes problemáticas no âmbito $C / T / S / A$ trata das problemáticas discutidas que devem ser utilizadas como artifícios motivadores da aprendizagem. Este "triângulo de tensões" representa as interações entre os três polos presentes no $1^{\circ}$ momento que, por sua vez, podem tanto se aproximar uns dos outros quanto 
se afastare, como também percorrer sentidos diversos. A problematização de tais interações deve permitir o levantamento e discussão de dúvidas e questionamentos dos alunos sobre determinado tema que será estudado e articulado com o auxílio do professor.

A partir das discussões promovidas durante a problematização, são elaboradas questões de pesquisa abordando todos os aspectos debatidos pelos alunos, para as quais eles não possuíam as respostas ou o conhecimento necessário para se chegar a elas. Tais questões, denominadas de questões-problema, atuam como uma ponte para o segundo momento do EPP e possuem a função de instigar a preparação e o planejamento da pesquisa dos alunos. O planejamento das pesquisas e as ações realizadas fazem parte do segundo momento, denominado de metodologias de trabalho. Neste momento, são buscadas, por diversos caminhos, as respostas para às questões-problema elaboradas anteriormente, baseadas em metodologias diferentes que ora se concentram mais na figura do professor ora se concentram mais nas atitudes e reflexões dos alunos.

O terceiro e último momento, avaliação da aprendizagem e do ensino, possui o objetivo de avaliar se as respostas para as questões-problema foram obtidas, se são adequadas ou não, além de refletir sobre os diferentes caminhos percorridos para a obtenção das mesmas. Trata-se de uma avaliação que reflete sobre os produtos obtidos bem como os processos que foram utilizados durante as atividades.

Figura 1. Momentos pedagógicos do Ensino por Pesquisa

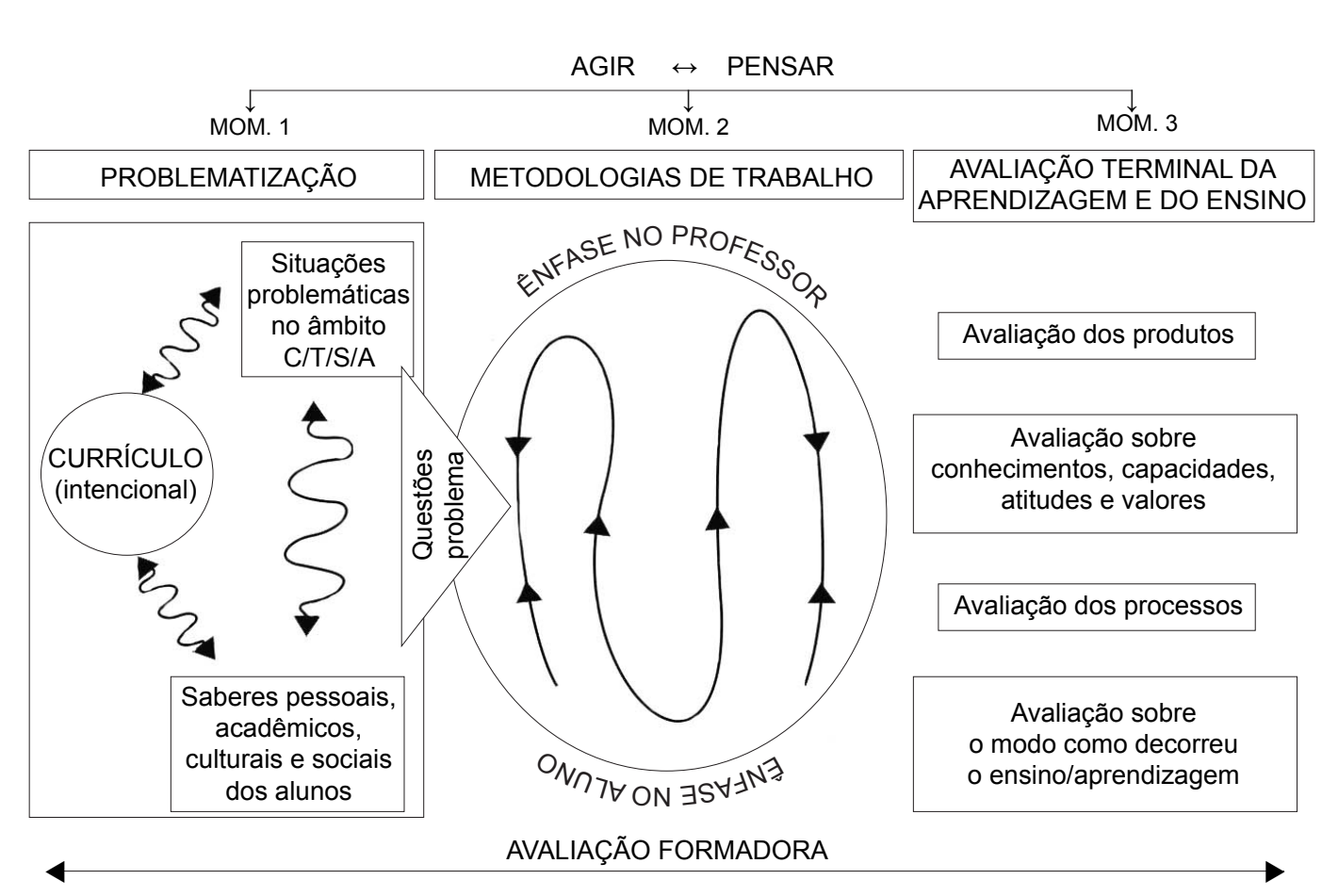

Fonte: adaptado de Cachapuz, Praia e Jorge (2002). 
Uma vez apresentados os principais elementos presentes no EPP, são apresentadas e discutidas, a seguir, a metodologia empregada e a forma como os dados do presente trabalho foram coletados e analisados.

\section{Metodologia}

\section{Contexto da intervenção}

A intervenção aqui analisada foi realizada no contexto do estágio em Física, mais precisamente, numa escola pública de Goiânia vinculada a uma universidade pública local. A unidade escolar atende cerca de setecentos alunos nos ensinos Fundamental e Médio, sendo que cada série possui duas turmas, com, no máximo, trinta alunos cada. O processo de ingresso na escola ocorre por meio de sorteio, o que permite, em tese, o acesso de todas as classes sociais a essa instituição.

O fato de a escola estar vinculada a uma universidade pública local faz com que a mesma tenha, como uma das suas principais prerrogativas, a aprovação de seus alunos no vestibular da universidade à qual está vinculada, de modo que valoriza e preza o trabalho de determinados conteúdos em sala e o cumprimento de eventos em datas específicas e preestabelecidas do calendário escolar, tais como a avaliação bimestral que simula o exame do vestibular - "o simulado". Por outro lado, por se tratar de uma escola do tipo "aplicação", a unidade de ensino acolhe diversos licenciandos dessa universidade na condição de estagiários, possuindo, diferentemente de outras escolas públicas, uma política própria de estágio, igualmente valorizada e rigorosamente seguida pelos seus professores. Desse modo, a escola e os professores que nela atuam impõem, aos estagiários, diversas demandas, tais como: cronogramas de atividades, cumprimento de currículos preestabelecidos e do calendário escolar, etc.

Nesse contexto, as atividades de ensino e aprendizagem foram trabalhadas com os alunos das duas turmas da $2^{\mathrm{a}}$ série do Ensino Médio durante o período de um semestre letivo - de agosto a dezembro de 2010. Tais turmas foram escolhidas por serem as turmas em que lecionava o professor de Física que supervisionou o trabalho do licenciando envolvido nessa intervenção, enquanto estagiário na escola. Por meio de levantamento feito junto aos alunos dessas turmas, constatamos que os mesmos possuem faixa etária entre 15 e 18 anos, sendo que a maioria é proveniente de famílias com renda familiar mensal entre três e dez salários-mínimos aproximadamente; possuem acesso aos meios de comunicação e informação amplamente utilizados pela sociedade, tais como televisão e a internet, e utilizam diversas tecnologias em seu cotidiano.

A intervenção buscou a alfabetização científica e tecnológica (ACEVEDO DÍAZ; VÁZQUEZ ALONSO; MANASSERO MAS, 2003; FOUREZ, 2003) dos alunos por meio do estudo de determinados temas, abordando a Ciência e Tecnologia, em questões de caráter social, histórico e ambiental, uma vez que os alunos se mostravam desinteressados em relação à apresentação tradicional dos conteúdos de Física, invariavelmente voltada para a realização do vestibular. Enfim, pretendia-se avançar em alguns problemas vivenciados na sala de aula: a desmotivação/apatia durante as atividades que eram desenvolvidas nas aulas tradicionais de Física e a falta de criticidade dos alunos quanto à percepção das relações entre a Ciência, a Tec- 
nologia, a Sociedade e o Ambiente. Tais problemas se devem, em parte, à dinâmica utilizada nas aulas tradicionais de Física que, devido ao perfil da instituição escolar, vão em sentido contrário àquele preconizado pelos Parâmetros Curriculares Nacionais (BRASIL, 1999), a saber, um ensino contextualizado, investigativo e interdisciplinar, além de valorizar aspectos éticos e morais.

As atividades desenvolvidas foram elaboradas em uma parceria que contou com: o licenciando em Física cursando a disciplina de estágio; o professor supervisor de estágio da escola, que leciona a disciplina de Física nas referidas turmas; e o pesquisador acadêmico da universidade, que leciona a disciplina de estágio para o curso de licenciatura em Física. Mais precisamente, o estagiário ficou responsável pela orientação dos alunos durante encontros agendados no contraturno das aulas regulares e mantendo contato com eles via e-mail; o professor supervisor elaborou e ministrou aulas sobre o conteúdo de Física que, apesar de ainda serem ministradas nos moldes tradicionais, se articulavam com as temáticas de investigação dos alunos; e o professor universitário contribuiu com a orientação teórica da atividade e, durante as aulas de Estágio, problematizava as situações vivenciadas pelo estagiário durante o desenrolar da intervenção. O debate que uniu as duas turmas para discussões sobre alguns dos temas pesquisados, e que foi utilizado como evento finalizador do processo, foi mediado pelo licenciando e pelo professor acadêmico. Cabe ressaltar, ainda, que todas as atividades desenvolvidas foram construídas e debatidas em reuniões que contavam com a participação desses três agentes, atuando sempre em constante diálogo, com o intuito de tomar decisões sobre questões emergentes que surgiam ao longo do desenvolvimento da proposta.

Logo, a proposta teve o objetivo de tornar mais significativo o ensino e aprendizagem em ciências, abordando temas e conceitos de uma maneira que auxiliassem os alunos a compreenderem de uma forma mais abrangente o mundo em que vivem e, assim, dar sentido a ele. Buscou-se, ainda, desenvolver, nos alunos, uma percepção crítica das relações CTSA, focando em estudo e discussões de problemas associados aos aparelhos tecnológicos de nossa sociedade, evidenciando "a distância que há entre o objeto técnico descrito por uma disciplina científica e a tecnologia com toda a sua complexidade social, cultural e econômica" (FOUREZ, 2003, p. 120).

Desse modo, no começo da intervenção, foi solicitado, aos alunos, que se organizassem em grupos para realizarem pesquisas acerca de 1 dentre 12 temas predeterminados, relacionados, seja por princípio ou funcionamento, com o espectro eletromagnético: (1) Rádio AM/FM; (2) Televisão analógica e digital; (3) Forno micro-ondas; (4) Radar de aviões; (5) Telefone celular; (6) Visão noturna (infravermelho); (7) Cinema 3D; (8) Telescópio; (9) Microscópio; (10) Câmera fotográfica e filmadora; (11) Aparelho de raios x; (12) Radioterapia com radiação gama.

Assim, os temas foram apresentados às turmas e, em seguida, atribuídos aos grupos por meio de sorteio ${ }^{2}$. Uma vez definidos os temas de cada grupo, os alunos, em constante diálogo com os professores e o licenciando, realizaram suas pesquisas com o objetivo de produzirem um relatório escrito. Nessa pesquisa foi solicitado, aos alunos, que abordassem e discutissem os seguintes aspectos: (a) História da Ciência e da Tecnologia; (b) Contextos Sociais; (c) Impactos Socioambientais; (d) Ligação entre o conteúdo do trabalho com o que foi ensinado nas aulas

\footnotetext{
${ }^{2}$ A numeração utilizada nos temas será empregada ao longo deste texto para a designação dos grupos, ou seja, quando citarmos o Grupo 1, estaremos nos referindo ao grupo que pesquisou sobre o tema (1) Rádio AM/FM, e assim por diante.
} 
regulares de Física. Durante essa etapa de estudo e discussão dos temas nos grupos, foram construídos, com os alunos, vários momentos de discussão e orientação, em horários diversos das aulas regulares (contraturno), além de se disponibilizar um e-mail de contato para que pudessem dialogar com o licenciando, esclarecer dúvidas, fazer questionamentos, dar sugestões e opiniões etc. O objetivo desses momentos de discussão em grupo foi o de construir um ambiente de alfabetização científica e tecnológica coletiva, importante para desenvolver, nos alunos, uma cultura de comunicação, tornando-os capazes de deliberar coletivamente sobre os problemas da sociedade, e, por meio do diálogo, articularem competências coletivas e coletivamente (FOUREZ, 2003).

Após o processo de construção, discussão e sistematização das pesquisas, foram sorteados dois grupos (Grupo 9, "Microscópio" e Grupo 11, "Aparelho de raios x"), sendo um grupo de cada turma, com o objetivo de promover um debate com os temas dos grupos sorteados. Posteriormente, foi proporcionado um momento no qual os alunos puderam construir, de forma coletiva, regras para guiar esse debate. Uma vez estabelecidas as regras do debate pelos alunos, o mesmo foi promovido com o intuito de discutir os temas dos grupos sorteados. O debate consistiu numa atividade finalizadora do processo de ensino e aprendizagem, e proporcionou um momento no qual os alunos pudessem expor ideias, argumentar e problematizar as relações entre a Ciência, a Tecnologia, a Sociedade e o Meio Ambiente.

Tais atividades aqui descritas, além de visarem o estabelecimento de um ambiente propício ao envolvimento dos alunos com o estudo dos diversos aspectos CTSA ligados aos temas de pesquisa, proporcionaram a construção dos dados analisados no presente trabalho. Os métodos de construção e análise de dados são apresentados a seguir.

\section{Método de pesquisa e instrumentos de coleta de dados}

Visando responder a pergunta: "Em que medida as atividades de pesquisa pautadas em aspectos CTSA que foram trabalhados junto a alunos do Ensino Médio proporcionam melhor compreensão dos elementos teóricos da perspectiva do Ensino por Pesquisa?”, foi realizada uma investigação de caráter qualitativo (GÓMEZ; FLORES; JIMENEZ, 1999).

A construção dos dados foi realizada por meio de diversos instrumentos de coleta de dados:

- notas de campo (BOGDAN; BIKLEN, 1994), construídas pelos professores, nas quais constam as descrições dos eventos e atividades propostas, os comportamentos e reações dos alunos, bem como as relações desenvolvidas entre eles próprios e entre eles e os professores durante cada etapa;

- diários de aprendizagem (GENOVEZ, 2005), construídos pelos próprios alunos enquanto realizavam suas pesquisas e discussões para a elaboração dos relatos escritos, que consistem em registros sobre suas impressões, opiniões e dificuldades encontradas durante o processo de pesquisa dos temas propostos;

- gravações em áudio e vídeo realizadas durante o debate com os alunos, que possibilitaram uma análise cuidadosa e detalhada sobre o comportamento, a fala e o envolvimento dos alunos durante essa importante etapa do processo de ensino e aprendizagem; e

- relatórios escritos pelos alunos, que constituíram o produto final de todo um processo de estudo e da discussão acerca dos temas trabalhados. 
Assim, a partir do confronto entre a teoria do EPP e os dados, foram construídas as categorias de análise apresentadas a seguir.

\section{Categorias de análise}

As categorias aqui apresentadas foram construídas sob as duas dimensões presentes no EPP: AGIR e PENSAR, dialógicas entre si (Figura 1).

A dimensão AGIR reporta-se a uma dimensão atitudinal e refere-se a procedimentos e posturas estabelecidas e desenvolvidas pelos alunos ao longo das atividades de ensino e aprendizagem. Por sua vez, a dimensão PENSAR reporta-se a uma dimensão cognitiva e refere-se a toda forma de conhecer (analogias, estimativas, hipóteses, etc.) estabelecida, desenvolvida e empregada pelos alunos. As categorias construídas sob tais dimensões são apresentadas no Quadro 1.

Quadro 1. Categorias de análise construídas

\begin{tabular}{|l|l|}
\hline \multicolumn{2}{|c|}{ AGIR } \\
\hline Dimensão atitudinal & Dimensão cognitiva \\
\hline Motivação/Mobilização dos alunos & Situações problemáticas no âmbito CTSA \\
\hline Pluralismo metodológico & Currículo \\
\hline Ambientes democráticos de participação & $\begin{array}{l}\text { Saberes pessoais, acadêmicos, culturais e sociais } \\
\text { dos alunos }\end{array}$ \\
\hline \multicolumn{2}{|c|}{ Avaliação crítica das informações de pesquisa } \\
\hline
\end{tabular}

Fonte: Elaborado pelos autores.

Quanto à dimensão AGIR, foram construídas as categorias: Motivação/Mobilização dos alunos, Pluralismo metodológico e Ambientes democráticos de participação.

A categoria "Motivação/Mobilização dos alunos" trata do envolvimento que os alunos apresentaram ao longo das atividades de pesquisa e discussão sobre os temas. A "equação de Vroom" (1964 apud CACHAPUZ; PRAIA; JORGE, 2004) que aqui é tomada por "(Motivação $\leftrightarrow$ Mobilização) = Expectativa x Valor", serve-nos como indicativo para se analisarem os momentos de motivação/mobilização dos alunos. A seta em duplo sentido sinaliza uma constante mudança entre motivação e mobilização, acompanhando as oscilações que os fatores "Expectativa" e "Valor" tiveram durante a intervenção. À medida que o fator "Expectativa" aumenta, os alunos tendem a se demonstrar motivados. Por sua vez, à medida que o fator "Valor" cresce, a motivação tende a uma mobilização efetiva dos alunos. Consequentemente, conforme observado por Cachapuz, Praia e Jorge (2004), se algum dos fatores da multiplicação for nulo (Expectativa x Valor), o produto também será nulo, de modo que, neste caso, não se obtêm a motivação e a mobilização.

A categoria pluralismo metodológico abarca os diferentes caminhos percorridos pelos alunos durante o processo de ensino e aprendizagem, desde a busca de informações para suas pesqui- 
sas, a forma de integração entre os temas pesquisados e os tópicos sugeridos, e a articulação de variadas fontes de pesquisa e tipos de conhecimento. Consiste em todas as diferentes atividades executadas pelos alunos durante o estudo e discussão do tema pesquisado.

A categoria ambientes democráticos de participação trata de momentos coletivos estabelecidos durante a intervenção em que os alunos tiveram a oportunidade de expor suas opiniões, e de tomar decisões importantes em seu próprio processo de ensino e aprendizagem.

Quanto à dimensão PENSAR, foram inicialmente construídas as categorias: situações problemáticas no âmbito CTS A, currículo e saberes pessoais, acadêmicos, culturais, e sociais dos alunos. Tais categorias seguem as mesmas características dos polos de interações presentes no primeiro momento do EPP e explícitos na fundamentação teórica.

Porém, os aspectos apresentados por essas categorias durante a intervenção, mostraram que elas não atuaram verdadeiramente como "polos de interações" (Figura 1), uma vez que a denominação de polos indica instâncias circunscritas, definidas e afastadas, e, conforme a teoria do EPP original, interagem apenas ora se aproximando ora se afastando (Figura 2a). $\mathrm{Na}$ intervenção realizada, tais categorias atuaram mais precisamente como núcleos integrados, que ora atuam separados ora se integram, o que indica uma relação e uma apropriação mais profunda das dimensões destacadas (Figura 2b).

Assim, foram elaboradas novas categorias: saberes pessoais, acadêmicos, culturais e sociais dos alunos/currículo; currículo/situaçôes problemáticas no âmbito CTS A; saberes pessoais, acadêmicos, culturais e sociais dos alunos/situações problemáticas no âmbito CTS A; e situações problemáticas no âmbito CTS A / curriculo/ saberes pessoais, acadêmicos, culturais e sociais dos alunos.

A categoria saberes pessoais, acadêmicos, culturais e sociais dos alunos/curriculo engloba os interesses dos dois núcleos envolvidos. Consiste em relações estabelecidas pelos alunos entre os conhecimentos curriculares que percebem e compreendem em seu cotidiano, agregados ao seu próprio saber pessoal, sociocultural; ou o inverso, um saber cotidiano que é mobilizado quando em contato com os conhecimentos sistematizados do currículo; ou ainda, a junção dos distintos saberes, tanto provenientes do currículo quanto provenientes de sua vivência para a solução de algum problema ou compreensão de determinado fenômeno.

Figura 2. Ilustração dos polos interacionais (a) e dos núcleos integrados (b).

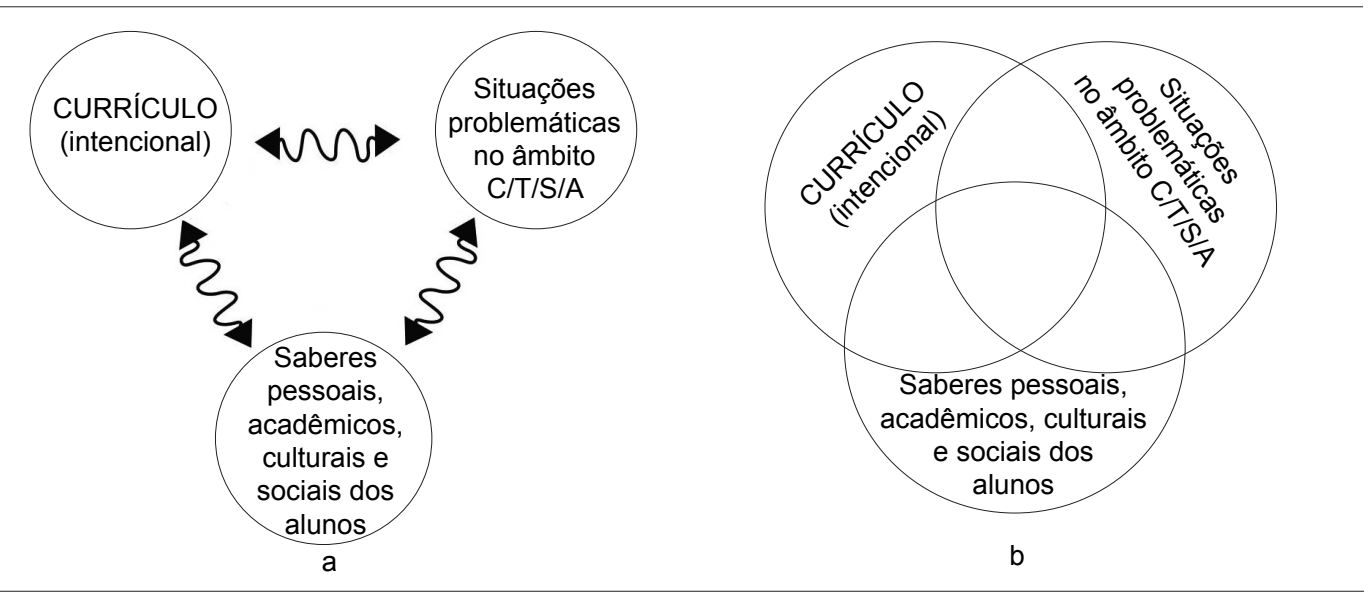

Fonte: elaborada pelos autores. 
A categoria currículo/situaçôes problemáticas no âmbito CTS $A$ integra toda a complexidade assumida pelos conhecimentos do currículo intencional quando confrontado com problemáticas de maior impacto social e ambiental. Por meio desse contato, os saberes provenientes do currículo são ampliados para além dos saberes estritamente científicos, passando a integrá-lo, também, os saberes sociais, éticos e morais, ambientais etc., devido à presença de questionamentos mais amplos, ligados aos apontamentos CTSA, os quais apenas o uso de conhecimentos científicos é pouco efetivo para o tratamento de tais problemáticas.

A categoria saberes pessoais, acadêmicos, culturais e sociais dos alunos/situaçoes problemáticas no âmbito CTS $A$ envolve os saberes carregados pelos alunos, adquiridos ao longo de sua vivência em sociedade e na escola para o enfrentamento de problemáticas sociocientíficas. Tal articulação possibilita a problematização dos próprios saberes do aluno frente ao tratamento de situações reais e próximas a eles, possibilitando o levantamento de questões importantes a serem tratadas pelo processo de pesquisa.

A categoria situações problemáticas no âmbito CTS A / currículo/ saberes pessoais, acadêmicos, culturais e sociais dos alunos articula as situações problemáticas por meio dos saberes familiares aos alunos, estabelecendo conexões que vão se sistematizando e adquirindo um caráter mais crítico e adequadamente orientado à medida que vão se incorporando elementos provenientes do currículo e todos os seus avanços adquiridos por intermédio dos apontamentos CTSA (saberes científicos, sociais, éticos e morais, ambientais), proporcionando compreensões mais abrangentes e significativas aos alunos.

Por fim, a categoria avaliação crítica das informações de pesquisa foi construída sob a dialogicidade existente entre o AGIR e o PENSAR. Trata-se da forma como os alunos escolheram as referências a serem utilizadas em suas pesquisas, o modo como os grupos trataram e avaliaram a coerência, e a veracidade das informações nelas presentes. Analisa-se, assim, a postura e a atitude crítica e reflexiva dos alunos quanto às informações científicas divulgadas.

Logo, os dados construídos ao longo da intervenção foram analisados por meio das categorias aqui apresentadas, e os resultados são apresentados a seguir.

\section{Resultados e discussões}

\section{Quanto à dimensão AGIR (dimensão atitudinal)}

Das categorias de análise construídas a partir da Dimensão AGIR, são apresentados os seguintes resultados:

\section{Motivação/Mobilização dos alunos}

A motivação dos alunos foi percebida ainda no início das atividades. Durante a apresentação da proposta, os alunos demonstraram ansiedade, empolgação e curiosidade. Tal motivação se apresenta novamente no momento do sorteio dos temas de pesquisa sobre o qual cada grupo iria pesquisar, conforme é indicado no seguinte trecho das notas de campo: 
Depois de terminado [...] li com eles todos os temas que seriam sorteados para a realização do trabalho. Nesse momento escutei vozes de alguns alunos conversando entre si: 'Eu quero cinema 3-D!', 'Escolhe visão noturna!'.

E, após sorteados os temas:

E após ter retirado o papel, o Aluno 13, em tom de comemoração, avisa aos integrantes do seu grupo que o tema deles seria o aparelho de raios $x$.

Percebe-se, nesse trecho, a importância de temas ligados de alguma forma ao cotidiano dos alunos, como, no caso, os temas citados e almejados por eles - cinema 3-D, visão noturna e aparelho de raios $\mathrm{x}$ - sobretudo como meio de buscar uma motivação mais imediata durante o processo de ensino e aprendizagem (CACHAPUZ; PRAIA; JORGE, 2002).

A motivação/mobilização dos alunos foi percebida em outros momentos, como nos encontros para orientação. Apesar de se tratar de uma atividade em horário distinto ao das aulas regulares de Física, vários alunos frequentavam os encontros para orientação, o que mostra uma mobilização e interesse sobre o trabalho que estava sendo desenvolvido por eles. É importante ressaltar também que alguns alunos procuravam os professores, durante os intervalos das aulas, a fim de esclarecerem dúvidas de diversos aspectos da pesquisa, sobretudo em relação ao tópico que deveria relacionar o tema pesquisado por eles com as teorias ensinadas em sala de aula.

Outro momento em que é notável a motivação e a mobilização dos alunos ocorreu durante a discussão das regras para o debate. $\mathrm{O}$ momento em que os alunos se reuniram para tomar decisões importantes sobre o próprio processo de ensino e aprendizagem, mostrou-se bastante importante para a motivação e envolvimento dos alunos com as atividades propostas. À medida que as discussões aconteciam, os alunos foram percebendo que suas falas eram consideradas importantes e efetivamente adotadas à estrutura do debate; assim, os alunos se sentiam menos assujeitados e mais atuantes no processo, culminando em resultados significativos quanto a sua motivação e mobilização. Logo, a intervenção foi capaz de motivar e mobilizar os alunos por meio de momentos pedagógicos capazes de explorar a discussão e a argumentação, estabelecendo e articulando conexões emotivas e psicológicas, de modo que o processo de ensino e aprendizagem passou a ter significado para eles (ZEIDLER et al., 2005).

As discussões envolvendo contextos e problemáticas reais, por sua vez, se mostraram bastante motivadoras e mobilizadoras para os alunos. À medida que as situações estudadas e discutidas pelos alunos estiveram mais próximas de suas realidades, a mobilização dos mesmos tornou-se mais evidente. Observa-se tal comportamento durante o debate quando o Grupo 11 fez uma breve apresentação sobre o tema "raios x" e todas as problemáticas relacionadas à sua descoberta, aplicação e impactos na sociedade. Essas informações sobre uma tecnologia com a qual vários alunos afirmaram ter tido contato em algum momento em suas vidas, geraram interesse, manifesto no comportamento eufórico dos alunos durante o debate, além de uma mobilização no sentido de se discutirem diversos aspectos e dúvidas sobre o assunto.

O mesmo ocorreu quando a discussão entre os alunos avançou para assuntos como os efeitos da radiação em seres humanos, a ponto de citarem, frequentemente, o acidente radiológico ocorrido em Goiânia em 1987 (INTERNATIONAL ATOMIC ENERGY AGENCY, 1988). Apesar de os estudantes não serem nascidos na época do acidente, o assunto, de tempos 
em tempos, ainda permeia os meios de comunicação e informação locais. Logo, essas alusões feitas por diferentes atores sociais ao tema, indicaram, de certa forma, uma "curiosidade mal saciada" acerca do assunto, que os alunos carregaram consigo e que, nitidamente, contribuiu para a mobilização de toda a turma sobre as discussões dessa problemática. Enfim, a presença de elementos controversos e problemas contextualizados e reais próximos à realidade dos alunos mostrou-se eficaz como meio de motivação e mobilização (FOUREZ, 2003).

Essa motivação/mobilização, porém, não ocorreu da mesma forma com as discussões sobre o aparelho microscópio. Para o Grupo 9, os alunos das turmas não mostraram o mesmo envolvimento realizando apenas questionamentos mais técnicos. Em nenhum momento foram levantadas questões problemáticas de caráter socioambiental, e, consequentemente, os alunos pouco se mobilizaram ou se demonstraram motivados para a discussão do tema "Microscópio". Em alguns momentos registrados nas gravações em vídeo, nota-se, durante a etapa do debate reservada a perguntas dirigidas ao Grupo 9, alunos interessados em levantar questionamentos ao Grupo 11 (raios x).

Tais fatos evidenciam a importância do uso de temas problemáticos ou controversos como uma forma de motivação intrínseca dos alunos, proporcionando um maior interesse, motivação e mobilização dos mesmos pelo processo de aprendizagem, sendo essa uma das mais importantes e relevantes prerrogativas do EPP (CACHAPUZ; PRAIA; JORGE, 2002).

\section{Pluralismo metodológico}

Laburu, Arruda e Nardi (2003, p. 252) defendem o uso de estratégias de ensino plurimetodológicas no ensino de ciências como a forma adequada de se promoverem aprendizagens significativas aos mais diferentes tipos de alunos que "são, de certa forma, incomensuráveis entre si”. Essa característica também foi contemplada na intervenção aqui analisada.

As atividades de ensino e aprendizagem articuladas com os alunos, tais como o planejamento das atividades e escolha dos temas nas aulas regulares de Física (momento em que os professores buscavam evidenciar ligações entre os temas pesquisados e os conteúdos ministrados nas aulas); os encontros em horários extraclasses para orientação das pesquisas; orientações em sala de aula durante duas aulas de Física em cada uma das turmas envolvidas; a utilização de mediação tecnológica, como o uso de e-mail de forma a facilitar a comunicação com os alunos; o processo de investigação desenvolvido pelos alunos para a produção de seus relatórios de pesquisa; e, por fim, o debate entre os alunos, utilizado como evento finalizador de todo o processo; são atividades que configuram um pluralismo metodológico.

O uso de atividades de ensino e aprendizagem plurais, por sua vez, sustentaram e auxiliaram os alunos a também exercerem práticas plurimetodológicas em suas pesquisas. Nota-se tal característica em seus relatórios de pesquisa. Neles foi possível identificar o uso de diversas fontes de pesquisa, entre livros, revistas, e informações disponíveis na Internet etc., que estavam explicitas em suas referências e em citações ao longo do texto, contribuindo para que alguns trabalhos articulassem informações diferentes, acrescentando apontamentos importantes para as discussões CTSA. Entre estes, pode-se citar o Grupo 5 “Telefone celular" e o Grupo 3 "Forno micro-ondas", que complementaram seus trabalhos com dados de órgãos reguladores nacionais e internacionais, tais como a Organização Mundial de Saúde (OMS), e o Instituto Nacional de Metrologia, Qualidade e Tecnologia (INMETRO). Outros, como o Grupo 10 "Câmera foto- 
gráfica e filmadora", utilizaram comparações de materiais próprios, como gravações pessoais em fitas magnéticas antigas e em mídias digitais mais modernas, para analisarem os principais avanços tecnológicos e modificações relacionadas ao tema de pesquisa.

Nota-se, ao longo da intervenção, que as atividades estiveram ora centradas nos professores (planejamento e escolha dos temas; aulas regulares) ora centradas nos alunos (investigações sobre os temas; produção dos relatórios escritos; debate) e, por vezes, em diálogos entre pesquisadores e alunos (encontros para orientação). Essas atividades de ensino e aprendizagem plurimetodológicas proporcionaram diversos momentos propícios à construção e desenvolvimento de conceitos, competências, atitudes e valores necessários para a vivência em sociedade e para a formação do cidadão cientificamente culto (CACHAPUZ; PRAIA; JORGE, 2004), e estimularam os alunos a buscarem, por diversos caminhos, a compreensão de diferentes aspectos CTSA envolvidos em seu tema de pesquisa. Desse modo, a atividade permitiu estabelecer momentos em que os alunos tiveram de se organizar, levantar informações, avaliar as informações levantadas, sistematizar tais informações de maneira coerente, debater, argumentar e defender um ponto de vista etc. Os alunos conseguiram, assim, articular diversos tipos de conhecimentos, desde conhecimentos científicos com implicações sociais e ambientais, como os efeitos dos mais variados tipos de radiação eletromagnética em seres humanos e conceitos de linguagem científica socialmente utilizados, como o símbolo internacional de presença de radiação ionizante, até os apontamentos sobre os cuidados necessários ao se introduzir uma nova tecnologia na sociedade, como foi apresentado pelo Grupo 11 durante o debate sobre a problemática origem e aplicação tecnológica dos raios x.

\section{Ambientes democráticos de participação}

No início da atividade, os grupos de pesquisa se apresentavam como ambientes pouco democráticos, pois não possibilitavam (ou não incentivavam) a participação ativa de todos os seus membros. Os grupos, em sua maioria, se organizaram de forma que um de seus membros atuasse como líder, sendo o integrante que mais se relacionava diretamente com os professores.

Porém, ao longo da intervenção, foram estabelecidos ambientes democráticos de discussão, expressão de opinião e tomadas de decisão, nos quais os alunos tiveram a oportunidade de participar ativamente do seu processo de ensino e aprendizagem.

Tal situação ocorreu durante o momento reservado para a discussão e definição das regras do debate. No início, os alunos demonstraram certa resistência em escutar e aceitar opiniões diferentes para encontrarem um consenso, como é possível notar no seguinte trecho das notas de campo:

Logo começaram a conversar muito, todos querendo falar ao mesmo tempo, [...]. Enquanto os alunos apresentavam suas ideias, percebia-se certa antipatia e desaprovação pela expressão no rosto de alguns alunos, quando certos alunos falavam e algumas sugestões eram colocadas.

Um dos professores tentou organizar a discussão com os alunos, tentando mostrarlhes quanto é importante tanto saber falar quanto saber escutar os colegas, para que aquele momento pudesse avançar: 
Foi quando o professor pediu silêncio e começou a falar sobre a importância daquele evento. De que tudo, ou quase tudo, que os alunos se envolviam ou participavam, já possuiam regras prontas. Que a opinião deles [dos alunos] era sempre desconsiderada. Falou também sobre a importância de se valorizar o debate e que aquela situação, com todos querendo falar ao mesmo tempo, era bastante normal. Entretanto, para conseguirmos escutá-los e dar atenção a cada um deles, seria necessário um pouco de ordem e respeito à fala do colega.

Logo, em diálogo com os professores, os alunos, aos poucos, foram adquirindo a postura democrática, respeitando a participação, a opinião e as ideias apresentadas pelos colegas até chegarem a uma definição sobre quais regras deveriam guiar o debate.

É importante ressaltar que a constituição do bloco de árbitros formado pelo conjunto dos alunos que estariam assistindo a apresentação dos dois grupos selecionados para o debate foi uma iniciativa de uma aluna e um aluno que sentavam em carteiras posicionadas no meio da sala, mas que tinham colegas que ficavam no fundo da sala de aula e pouco contribuíram para a construção dos trabalhos. Daí decorre que a iniciativa deles tinha como pano de fundo a preocupação de envolver os alunos que não tinham participado efetivamente na construção dos trabalhos, mas que via, no debate, a oportunidade de eles se envolverem e contribuírem com a discussão. Ou, nas palavras dessa aluna:

Já que a ideia é tornar a atividade mais participativa e democrática, deixar as pessoas
falarem. É justo que mesmo aqueles participaram pouco [realização do trabalho
escrito] possam se pronunciar no debate. Acho, acho... Quero dizer, o debate é uma
forma de envolver esses colegas na atividade. Sabe, eu acho que eles têm muitas ideias
legais. Acho que a gente pode aprender muito com eles. Se eles e o restante da sala
que não estiver apresentando podem participar fazendo parte do júri. Sei lá!! Juir.
Mas, o negócio é que todos participem, tenham a chance de participar. ${ }^{3}$

Os alunos mostraram-se mais motivados e envolvidos com a discussão que acontecia na medida em que percebiam que as suas opiniões e sugestões eram, de fato, consideradas relevantes e levadas a diante como direcionador potencial para a estrutura do debate. À medida que dialogavam, defendiam suas posições e suas ideias negociando pontos divergentes, a fim de tomarem uma decisão coletiva. Tais comportamentos sinalizam para o estabelecimento inicial de uma cultura de comunicação e respeito às ideias diversas que permitiram uma discussão pertinente da situação, orientada à deliberação de um momento importante para os alunos que, por sua vez, representa uma importante etapa na alfabetização científica e tecnológica coletiva (FOUREZ, 2003).

Tal processo de conquista do engajamento dos alunos também ocorreu durante o debate, e, novamente, os professores tiveram de auxiliar os alunos para que pudessem expressar suas opiniões no início do debate. Entretanto, contando com sugestões dos professores,

\footnotetext{
${ }^{3}$ Notas de campo dos autores.
} 
os alunos, pouco a pouco, demonstraram uma postura de respeito ao momento e à fala dos colegas, buscando o diálogo à medida que as dúvidas e questionamentos foram surgindo, em um momento no qual todos os alunos tiveram a oportunidade de expressar seus pontos de vista e debater sobre eles.

Constituíram-se, dessa forma, características relevantes para a formação de cidadãos cientificamente cultos, já que a participação no processo democrático, a tomada de decisões, os juízos de valor informados e fundamentados e o respeito às diferenças de opinião são atitudes necessárias para se viver e deliberar em sociedade (CACHAPUZ; PRAIA; JORGE; 2004, p. 367).

\section{Quanto à dimensão PENSAR (dimensão cognitiva)}

Das categorias de análise construídas a partir da dimensão PENSAR, são apresentados os resultados que seguem.

\section{Situações problemáticas no âmbito CTSA}

A utilização de situações problemáticas em uma abordagem CTSA no ensino de ciências é apontada como um mecanismo de contextualização e de reorganização do currículo escolar, ao se trabalharem aspectos históricos, políticos, éticos e socioeconômicos visando o desenvolvimento de valores humanos e de uma consciência social (SANTOS; SCHNETZLER, 2010). Nesse cenário, a abordagem de temas CTSA é capaz de potencializar a abordagem de conteúdos socialmente relevantes, além de fomentar processos de construção e (re)negociação de significados e representações, e possibilitar a reflexão crítica sobre contextos reais próximos e familiares aos alunos (SANTOS, 2007).

Durante as atividades realizadas, alguns alunos sinalizaram a construção de compreensões um pouco mais amplas sobre as contextualizações proporcionadas pela abordagem CTSA. Foram percebidos, entre alguns avanços: a construção de atitudes e valores a respeito de questões sociais; a construção e apropriação de conceitos científicos e de percepções sobre a Natureza da Ciência; e o estabelecimento de relações entre as experiências escolares relacionadas às ciências e os problemas cotidianos.

Dentre as atitudes e valores fomentados e construídos pelos alunos, emergiram, com maior ênfase, aqueles associados às atitudes questionadoras quanto à associação da lógica capitalista de produção de artefatos e materiais em larga escala, os desenvolvimentos tecnológicos e os seus graves impactos no meio ambiente. Mais precisamente, tais atitudes se manifestaram com maior intensidade nos Grupos: 1 (Radio AM/FM), 2 (Televisão analógica e digital), 5 (Telefone celular) e 10 (Câmera fotográfica e filmadora). Todos esses grupos abordaram os efeitos de uma cultura consumista em nossa sociedade, que tem levado, cada vez mais, à degradação do meio ambiente, o que gerou neles, durante as discussões, a necessidade de conscientização deles próprios enquanto agentes integrantes da chamada sociedade consumidora (BAUMAN, 2008).

Outra reflexão pertinente foi sinalizada no relatório escrito do Grupo 10, no qual abordaram as mudanças ocorridas no campo das artes, sobretudo a pintura, com a popularização e avanços das técnicas e tecnologias ligadas às máquinas fotográficas. Nesse sentido, o grupo apresentou, ainda, o modo como os filósofos da época acolheram a nova tecnologia e a implicação sobre seus valores: 
Roland Barthes, um filósofo francês, disse que via a câmera fotográfica como 'ideia de morte por mostrar algo gravado em um tempo que não mais voltará'. Seus valores quanto à arte e em meio à sociedade capitalista levou a se pensar que o homem talvez. não desse mais valor ao real como antes, devido às imagens, isso por fim leva a pensar nas mudanças nos valores. [Aluno 18 do Grupo 10]

Nesse trecho de seu relatório, o Aluno 18 do Grupo 10 indica que, por meio de suas pesquisas e discussões, foi capaz de perceber que, além de impactos sociais objetivados proporcionados pela tecnologia, deve-se refletir, também, sobre os impactos destes artefatos sobre os valores humanos que, quando aliados aos valores econômicos, geram impactos também psicológicos em diversos seguimentos da sociedade.

Quanto à construção e apropriação de elementos relacionados à Natureza da Ciência, alguns grupos apresentaram avanços obtidos sobre a compreensão do desenvolvimento da Ciência e da Tecnologia e suas relações com a Sociedade. Tal característica é evidenciada nos relatos extraídos dos Diários de Aprendizagem de alguns grupos, que sinalizam uma mudança na postura de ver a constituição e desenvolvimento do trabalho científico e tecnológico:

\section{[...] pesquisei sobre a história de origem da fotografia, levando-me a aprender que este foi um processo que se deu ao longo de séculos, tendo a presença de diversos nomes na criação, e não foi algo inventado individualmente; [...] o que proporcionou grande evolução até os dias de hoje. [Aluno 18 do Grupo 10]}

Os comentários apresentados nesse trecho do Diário de Aprendizagem sinalizam uma aparente mudança nas concepções do Aluno 18, que, inicialmente, percebia a Ciência, sobretudo a Física, como "obras de gênios isolados" - típico de uma visão individualista e elitista da Ciência (GIL-PÉREZ et al., 2001) - e que, agora, começa a perceber e a construir um entendimento sobre a Ciência como algo fundado numa construção coletiva e de cooperação.

A presença de discussões de problemáticas CTSA durante o debate também foi bastante marcante. Especialmente, com o tema do Grupo 11, "raios x", no qual foram discutidas a forma como as técnicas de produção e emissão desse tipo de radiação foi repassada e aplicada à sociedade - sobretudo, na área da medicina - apesar dos pouquíssimos conhecimentos científicos estabelecidos, na época, a respeito de sua origem, composição e, especialmente, suas reações em seres humanos. Dentro desse contexto histórico, os alunos conseguiram expor alguns impactos, a curto e longo prazo, sentidos pela sociedade. Situação semelhante ocorreu quando os alunos mencionaram o acidente radiológico ocorrido em Goiânia. Neste caso, foram abordados como a falta de informação da população e o descaso das autoridades públicas responsáveis pela fiscalização de aparelhos que utilizam fontes de radiação ionizantes - como no caso um aparelho de radioterapia - levaram a um desastre público que ocorreu na cidade em que eles moram. Tais discussões possibilitaram, aos alunos, perceberem a importância de se estabelecer uma cultura e uma consciência coletiva de responsabilidade e de atuação na sociedade, orientada para a prevenção desse tipo de problema. Como também contribuíram para conscientizá-los das diversas implicações que a Ciência e a Tecnologia possuem em nossa sociedade, seja para o bem seja para o mal (ACEVEDO DÍAZ; VÁZQUEZ ALONSO; MANASSERO MAS, 2003). 


\section{Currículo}

Um dos objetivos da educação CTSA consiste em selecionar e potencializar a abordagem de conceitos e fenômenos científicos socialmente relevantes, por meio do tratamento de problemáticas sociais reais e abertas, resultando em uma ampliação e diversificação curricular (SANTOS; MORTIMER, 2002). Logo, durante as atividades de discussão e pesquisa em grupo, os alunos construíram, mobilizaram e articularam conteúdos científicos diversos, além dos previstos na matriz curricular da disciplina de Física da escola.

Alguns grupos, entretanto, demonstraram maior facilidade em tratar os conceitos físicos envolvidos em seus respectivos temas e relacioná-los com os conteúdos estudados nas aulas regulares de Física. Dentre esses, percebem-se grupos cujos temas possuem associação direta com o conteúdo de Física do $2^{\circ}$ ano ministrado na escola, como: o Grupo 9, "Microscópio"; o Grupo 10, "Câmera fotográfica e filmadora", e o Grupo 8, "Telescópio", que trataram de associações de lentes e reflexões de espelhos. Destaca-se, também, o Grupo 4, "Radar de Aviões" que apresentou o efeito Doppler em suas investigações. O Grupo 5, "Telefone celular”, por sua vez, discutiu as principais diferenças existentes entre as ondas eletromagnéticas, abordadas em suas investigações, e as ondas mecânicas, estudadas nas aulas de Física.

O Grupo 7, "Cinema 3D", utilizou diferentes fontes de informação e pesquisa para uma compreensão mais clara dos fenômenos físicos envolvidos na tecnologia estudada. Consequentemente, o grupo obteve relevantes informações, contando com ilustrações detalhadas e explicações exclusivamente qualitativas sobre as ideias principais a respeito do assunto, a partir de uma matéria contida em uma revista de divulgação científica. Devido a essas apropriações de fontes de pesquisa durante as investigações, foi sugerida, a esse grupo, uma abordagem mais avançada para o tema, envolvendo o estudo do fenômeno da polarização da luz, o que permitiu ir além do currículo de Física para a $2^{a}$ Série do Ensino Médio da escola, uma vez que tal teoria não é abordada pelo professor de Física durante as aulas regulares. Outros conceitos físicos não discutidos tradicionalmente no currículo escolar dessas turmas, mas que foram contemplados pela intervenção, diziam respeito à Física Moderna e Contemporânea. Podem-se citar, por exemplo, a produção e emissão de raios x, apresentadas pelo Grupo 11, e a produção de radiação ionizante através de decaimento radioativo e radioterapia com radiação gama, abordada pelo Grupo 12. Logo, as atividades de cunho CTSA desenvolvidas com os alunos dessas duas turmas possibilitaram ir além do conteúdo curricular normalmente transmitido a eles.

Apesar de essa categoria tratar exclusivamente do currículo conceitual específico de ciências, destaca-se aqui que o currículo numa abordagem CTSA jamais deve ser reduzido ao seu aspecto conteudista. Além do conteúdo conceitual, inegavelmente importante, também são objetivos curriculares destacados na educação CTSA: a construção e o cultivo de valores, atitudes, consciência e percepção crítica da realidade. Como tais construções são objetos de análise das demais categorias aqui apresentadas, optou-se por omiti-las aqui neste espaço.

Desse modo, os alunos, em certa medida, conseguiram desenvolver, em suas investigações, os conteúdos de Física, ao relacioná-los a cada tema pesquisado. Foram capazes de perceber os principais princípios físicos envolvidos com as tecnologias estudadas, e, assim, avançar em mais um aspecto necessário para a formação do cidadão cientificamente culto: "aquisição e desenvolvimento de conhecimento conceitual" (CACHAPUZ; PRAIA; JORGE, 2004, p. 367). 


\section{Saberes pessoais, acadêmicos, culturais e sociais dos alunos}

Quanto à categoria referente aos saberes trazidos pelos alunos, os dados analisados não permitiram evidenciar a atuação de tais saberes isoladamente durante a intervenção. Entretanto, os dados analisados indicam a presença de tais saberes integrados com a categoria currículo.

\section{Saberes pessoais, acadêmicos, culturais e sociais dos alunos/currículo}

A consideração dos saberes incorporados previamente pelos alunos para a construção e apropriação de novos conhecimentos é considerada uma via promissora para a aprendizagem das atividades desenvolvidas, já que permite a aproximação e problematização dos conhecimentos científicos escolares e dos conhecimentos pessoais dos alunos que são oriundos de contextos culturais e sociais diferentes (CORTELLA, 2011).

Desse modo, a integração dos núcleos saberes pessoais, acadêmicos, culturais e sociais dos alunos e currículo proporcionou compreensões significativas aos alunos, que ocorreram durante as pesquisas sobre os temas. Nota-se tal compreensão no seguinte trecho do Diário de Aprendizagem do Aluno 18 do Grupo 10:

Outro ponto bastante interessante, é a vantagem da câmera digital sobre as primeiras analógicas [...] e isso é algo que pude comparar quando assisti o VHS do meu aniversário de 1 ano, que possui algumas falhas, e depois analisei o DVD do meu aniversário de 15 anos, no qual a imagem não possui falhas... [Aluno 18]

O trecho acima mostra como elementos do currículo presentes no trabalho se articularam com conhecimentos pessoais do Aluno 18, proporcionando uma aprendizagem mais significativa das características dos produtos construídos pelas diferentes tecnologias que dialogavam com seu tema de pesquisa.

A integração entre tais núcleos ocorreu também durante o debate. Foi possível notar a importância dos saberes provenientes da integração dos dois núcleos, apropriados pelos alunos, para a resolução de problemas levantados em suas discussões naquele momento.

É possível perceber tal característica no momento em que foi realizada a pergunta, durante o debate, aos membros do Grupo 11:

Por que a gente não pode usar objetos de metal quando vai tirar raios $x$ ? [Aluno 7 do Grupo 10]

Nesse instante, os membros do Grupo 11 ficaram em dúvida, sem saber realmente o que responder. Uma tentativa de resposta foi apresentada pelo grupo:

Eu acho que é porque o raio x... ele é eletropositivo, 'aí, ele atrai... [Aluno 13 do Grupo 11]

O assunto gerou pequenas discussões na turma toda, devido à falta de precisão, clareza ou, mesmo, sentido na resposta do Aluno 13: 
Por que quem tem placa no corpo tira raios x? [Aluno 5 do Grupo 5]

Eu tive que fazer uma cirurgia no joelho... e eu tenho um pino... um parafuso no meu joelho e é um metal... e eu faço raios $x$. [Aluno 3 do Grupo 2]

Logo, os alunos começam a conversar sobre o assunto e, alguns, como o Aluno 3, relataram experiências que tiveram em sua vida e que contrariavam as afirmações e tentativas de resposta até então sugeridas.

Levando em consideração a apresentação inicial do Grupo 11, sobre a formação da imagem na chapa pelos raios $\mathrm{x}$, e os recentes relatos dos colegas de classe, novos comentários surgiram:

Eu acho que o principal motivo não é esse, é porque a radiação ela entra no nosso corpo e ela... tipo assim grava na chapa, e ela não atravessa o osso e, assim como ela não atravessa o osso, ela não atravessa o metal e você não vê o que está por baixo daquela chapa de metal. [Aluno 6 do Grupo 2]

A partir da análise das falas acima, nota-se que o diálogo entre os alunos, expondo a sua visão particular do problema, provenientes de experiências em suas vidas, foi bastante importante. Desde a elaboração do breve problema inicial, as tentativas de se formular uma hipótese, os questionamentos em torno desta hipótese formulada, evidências e/ou eventuais falhas nas tentativas de resposta, e, a partir de uma construção que se deu coletivamente, integrando seus saberes cotidianos aos saberes adquiridos por meio do currículo trabalhado, chegaram a uma resposta que preencheria as lacunas expostas durante a discussão, e que fizesse parte de um consenso pelo grupo de alunos. Estabeleceu-se, ainda, uma reflexão e uma regulação das informações, pelos próprios alunos dialogando entre si, se assemelhando a uma estrutura própria da comunidade científica, o que caracteriza o "aprender a fazer Ciência" (CACHAPUZ; PRAIA; JORGE, 2004, p. 367).

\section{Currículo/Situações problemáticas no âmbito CTSA}

A integração do núcleo currículo ao núcleo situações problemáticas no âmbito CTS A, permitiu, aos alunos, avaliarem a natureza dos impactos socioambientais das tecnologias estudadas.

Vários aspectos referentes aos impactos sociais e ambientais nas abordagens feitas pelos grupos enfatizaram e avaliaram tanto os benefícios quanto os malefícios proporcionados pela socialização de cada tecnologia, no seu contexto vivencial. Trabalhos como o do Grupo 1, "Rádio AM/FM", apontam historicamente a revolução nas comunicações proporcionada pelo uso do aparelho no início do século XX, mas, também, os impactos observados atualmente, mesmo que estes não sejam decorrentes diretamente da emissão de radiação eletromagnética. O trecho abaixo, extraído do relatório escrito desse grupo, aponta problemáticas decorrentes do tema de estudo: 
possam funcionar, estes sim são grandes destruidores e poluidores do meio ambiente, [...] Chumbo (Pb), Níquel (Ni) e Mercúrio (Hg), [...] que quando abandonados de forma irresponsável [...] podem envenenar os seres humanos, além de muitos animais.

O grupo aponta, ainda, problemáticas surgidas por meio da relação do objeto com o atual contexto econômico brasileiro:

O grande problema [...] é com o que fazemos com as mais de 800 milhöes de pilhas e baterias que o Brasil produz ou importa todos os anos [...]

Nos trechos apresentados, os alunos do Grupo 1 apontaram problemas que não são decorrentes propriamente do fenômeno físico investigado, mas, sim, do contexto socioeconômico de produção da tecnologia, abordando os efeitos visíveis de uma cultura ocidental consumista presente em nossa sociedade (BAUMAN, 2008). Por meio dessa abordagem, os alunos identificaram os elementos presentes nessas tecnologias que são nocivas ao meio ambiente e aos seres humanos, além de exporem o atual cenário brasileiro de consumo não consciente dessa tecnologia.

Quanto à integração entre o núcleo currículo e o núcleo situações problemáticas no âmbito $C T S A$, estabelecida durante o debate, foram levantadas questões sobre os riscos aos quais estão sujeitos os profissionais que lidam com o aparelho de raios $\mathrm{x}$ :

Hoje em dia as pessoas que trabalham com esse tipo de máquina de raios $x$, aposentam mais cedo... pelo qual motivo? [Aluno 37 do Grupo 9]

Mesmo com as placas de chumbo e todo o equipamento de proteção, as pessoas que operam essas máquinas sofrem muita exposição à radiação emitida pelo aparelho. [Aluno 12 do Grupo 11]

A radiação afeta as células do corpo... por causa da vibração muito intensa dele... do raio X... tem uma frequência muito alta e 'aí ele acaba interferindo no DNA com o passar do tempo. [Aluno 15 do Grupo 11]

Nota-se, nesse trecho, que a integração dos dois núcleos aqui analisados, do conhecimento proveniente do currículo e das situações problemáticas, contribuiu não só para que os alunos do Grupo 1 chegassem a uma conclusão a respeito de um questionamento CTSA, como, também, permitiu a construção de conhecimentos relevantes, tanto socialmente quanto pessoalmente. Logo, as discussões permitiram a reflexão e a compreensão de problemáticas presentes na sociedade, como o exercício profissional de atividades que oferecem risco à saúde e as formas com que as sociedades desenvolveram leis trabalhistas para tal atividade profissional.

Por fim, abordagens e questionamentos como os mostrados aqui indicam uma preocupação que os alunos começaram a vislumbrar sobre aspectos da dimensão social, política e econômica do produto científico e tecnológico. Questionamentos esses, proporcionados pela abordagem CTSA integrada ao ensino e ao currículo de Física, que permitiram a discussão de dimensões da Ciência e da Tecnologia extremamente relevantes para a formação de um cidadão 
culto e crítico, preparando-o para viver em uma sociedade contemporânea, que se relaciona diariamente com os benefícios e impactos tecnológicos (CACHAPUZ; PRAIA; JORGE, 2002, 2004).

\section{Situações problemáticas no âmbito CTSA/Saberes pessoais, acadêmicos, culturais e sociais dos alunos}

Quanto à categoria Situações problemáticas no âmbito CTS A/Saberes pessoais, acadêmicos, culturais e sociais dos alunos, os dados analisados não permitiram evidenciar a integração estabelecida entre as situações problemáticas tratadas e os conhecimentos pessoais dos alunos. Tais características somente sugiram integradas junto do terceiro núcleo currículo.

\section{Situações problemáticas no âmbito CTSA/Currículo/Saberes pessoais, acadêmicos, culturais e sociais dos alunos}

A categoria Situações problemáticas no âmbito CTSA/Saberes pessoais, acadêmicos, culturais e sociais dos alunos evidencia que as situações problemáticas construídas pelos alunos, via saberes pessoais, vão se sistematizando e adquirindo um caráter mais crítico, à medida que vão incorporando elementos provenientes do currículo na perspectiva CTSA (saberes científicos, sociais, éticos e morais, ambientais), proporcionando, desta forma, compreensões mais abrangentes e significativas para os alunos.

Nota-se tal aspecto em diversas questões de interesse dos alunos que foram feitas ao Grupo 11 sobre o assunto raios x. Uma das questões levantadas foi sobre os seus efeitos no corpo humano:

Essas pessoas que perderam as mãos... o que aconteceu para fazer com que elas perdessem as mãos? E se a gente quando tira raio $x$, se tem algum risco, e se o efeito da radiação é cumulativo? [Aluno 5 do Grupo 8]

Tipo, o 'raio x'... a vibração dele é muito intensa, ela é muito forte, 'aí', quando ele entra na pele, ele atravessa a célula, acontece umas quebras do DNA que atrapalha todo o corpo, 'ai', acontece da morte do tecido, causa câncer, vários problemas... [Aluno 15 do Grupo 11]

Igual ele falou no comeco lá... os primeiros a vim os sintomas nas mãos foram os operadores mesmo das máquinas... [...] porque eles eram aqueles que, como eles manuseavam a exposição deles era mais repetitiva. [Aluno 12 do Grupo 11]

No trecho acima, percebe-se um problema levantado pelo Aluno 5, ao integrar os danos ocorridos aos operadores dos aparelhos de raios x no início do século XX (problemática CTSA) à sua preocupação pelo uso do aparelho em seu cotidiano (saberes pessoais). A resposta, mesmo que parcial, somente se torna possível a partir do momento em que os alunos integram os conhecimentos provenientes do currículo trabalhado durante as atividades de pesquisa aos conhecimentos provenientes dos núcleos anteriormente integrados, e propõem uma resposta que 
satisfaça aquela comunidade de alunos. Outro momento de destaque para a integração dos três núcleos ocorreu durante a discussão sobre o acidente radiológico de Goiânia, já que alguns alunos conheciam pessoas que foram vítimas dos efeitos da contaminação por césio-137 ou já viram os danos desse acidente em reportagens televisivas. Nesse caso, por meio de uma breve descrição das características da radiação gama, os alunos foram capazes de identificar como esta radiação afeta o organismo humano e pode promover diversos tipos de câncer, deformações físicas, entre outros problemas, para as pessoas que tiveram contato com aquele material radioativo.

Observa-se, nesses momentos, que os alunos constroem uma problemática envolvendo os raios x e a radiação gama a partir de informações pessoais, de seu cotidiano. Problemática essa, apenas esclarecida quando integrada aos conhecimentos provenientes do currículo adquiridos por eles, evidenciados na citação do aluno à uma explicação feita pelo professor durante as aulas regulares de Física.

Portanto, a integração dos núcleos permitiu uma visão mais ampla da situação problematizada, proporcionou uma breve abordagem interdisciplinar, compreensão de em quais situações há riscos à saúde, e a construção de conceitos socialmente relevantes.

\section{Quanto à dialógica AGIR/PENSAR (Dimensão atitudinal/cognitiva)}

Da categoria de análise construída a partir da relação entre as dimensões AGIR e PENSAR, é apresentada outra categoria:

\section{Avaliação crítica das informações de pesquisa}

Durante o processo de investigação dos temas, nota-se a preocupação de vários grupos quanto às fontes de pesquisas a serem utilizadas. O Diário de Aprendizagem do Grupo 8 sinaliza uma preocupação sentida por um de seus integrantes sobre quais fontes utilizar em sua investigação e quais seriam as mais confiáveis:

Procuraremos em outros livros da biblioteca [...] Particularmente penso que os livros podem ser mais confíveis neste trabalho, pois a informação é mais concentrada e específica. [Aluno 9 do Grupo 8]

Esta preocupação do Grupo 8 com a validade do conteúdo das referências a serem utilizadas se refletiu em seu trabalho, pois os alunos abordaram o tema de estudo, "Telescópio", por meio de diversas fontes, como: revistas e livros de divulgação científica, enciclopédias, sites de notícias e livros didáticos de Ensino Médio.

Outros grupos discutiram, também, dados provenientes de órgãos reguladores nacionais e internacionais. Um exemplo dessa postura foi o Grupo 5, “Telefone celular", que levantou e discutiu aspectos problemáticos do tema, por meio de pesquisas de estatísticas disponibilizadas pela Agência Nacional de Telecomunicações (ANATEL) e estudos divulgados pela OMS sobre possíveis efeitos nocivos à saúde humana provenientes da utilização do aparelho. Já o Grupo 3, "Forno micro-ondas", por sua vez, utilizou, em parte de sua pesquisa, informações disponibilizadas pelo INMETRO. 
Nota-se, desde o relato sobre a preocupação com a confiabilidade das informações a serem coletadas, como demonstrado pelo Grupo 8, e pelo uso de dados oficiais, como as informações mencionadas pelo Grupo 5 e pelo Grupo 3, uma atenção dada ao tipo e a forma com que a informação científica é divulgada atualmente para a sociedade. Atenção essa que perpassa a avaliação crítica dos meios de comunicação e informação, bem como o teor das informações por eles divulgadas. Logo, é necessária, além da percepção das complexas interações das relações CTSA, uma considerável quantidade de conhecimentos científicos, aos quais os alunos tiveram acesso por meio de suas investigações.

Assim, os relatos apresentados sinalizam que as atividades de pesquisa permitiram que alguns grupos refletissem e avaliassem não só quais informações são pertinentes, mas se são válidas e confiáveis, fomentando, assim, outra característica fundamental para a formação de um cidadão cientificamente culto: a análise e a avaliação crítica da divulgação científica e tecnológica (CACHAPUZ; PRAIA; JORGE, 2002).

\section{Considerações finais}

A análise e discussão dos resultados aqui apresentados sinalizam para um avanço no entendimento e encaminhamento dos momentos do Ensino por Pesquisa, configurado em um quadro teórico distinto, denominado Ensino por Pesquisa de Núcleos Integrados. Tais avanços estão ilustrados na Figura 3.

Em relação ao primeiro momento do EPP de Núcleos Integrados, foram evidenciados avanços quanto à problematização. No estudo de problemáticas reais, as dimensões explícitas pelos polos interacionais dificilmente são articuladas de forma isolada umas das outras, ou, mesmo, se caracterizam como circunscritas, delimitadas, independentes e afastadas, que, quando articuladas, estabelece apenas uma aproximação entre as mesmas, ou seja, ainda assim, permanecendo separadas. Portanto, o tratamento de problemáticas por intermédio do conceito de "polos interacionais" implica, de certa forma, um tratamento simplificado e redutor para um determinado problema que carrega, em si, toda a complexidade existente no mundo real. A presença dessas dimensões isoladamente ocorreu ao longo da intervenção, na medida em que as pesquisas dos alunos se restringiram às disciplinas tradicionais nas quais o tema pesquisado estava envolvido. Os Núcleos Integrados, por sua vez, ocorrem quando são abordados problemas reais, que possuem características mais amplas que os problemas tradicionalmente abordados no ensino de ciências, e que não definem fronteiras de conhecimentos a serem utilizados; e, portanto, exigem a mobilização de todos os recursos necessários ao seu enfrentamento. Logo, tal entendimento possibilitou o aprofundamento das problemáticas estudadas, proporcionando aprendizagens significativas para os alunos e uma compreensão mais ampla sobre o processo de ensino e aprendizagem graças à percepção da integração entre duas ou três das dimensões presentes nos núcleos. Os Núcleos Integrados proporcionam momentos em que os conhecimentos característicos de cada núcleo adquirem relações mais complexas do que uma simples aproximação e/ou afastamento caracterizada pela atuação dos polos na teoria original do EPP. É importante destacar, também, que tal integração ocorre de maneira mais eficaz à medida que os alunos motivados se mobilizam em torno de uma problemática percebida, apropriada e debatida. 
Quanto ao segundo momento do EPP de Núcleos Integrados, foram evidenciadas algumas categorias importantes para a formação de cidadãos cientificamente cultos, que podem ser desenvolvidas durante as metodologias de trabalho: a motivação/Mobilização dos alunos, o pluralismo metodológico; os ambientes democráticos de participação; a avaliação crítica das informações de pesquisa; e a interdisciplinaridade.

Figura 3. Sistematização do Ensino por Pesquisa de Núcleos Integrados

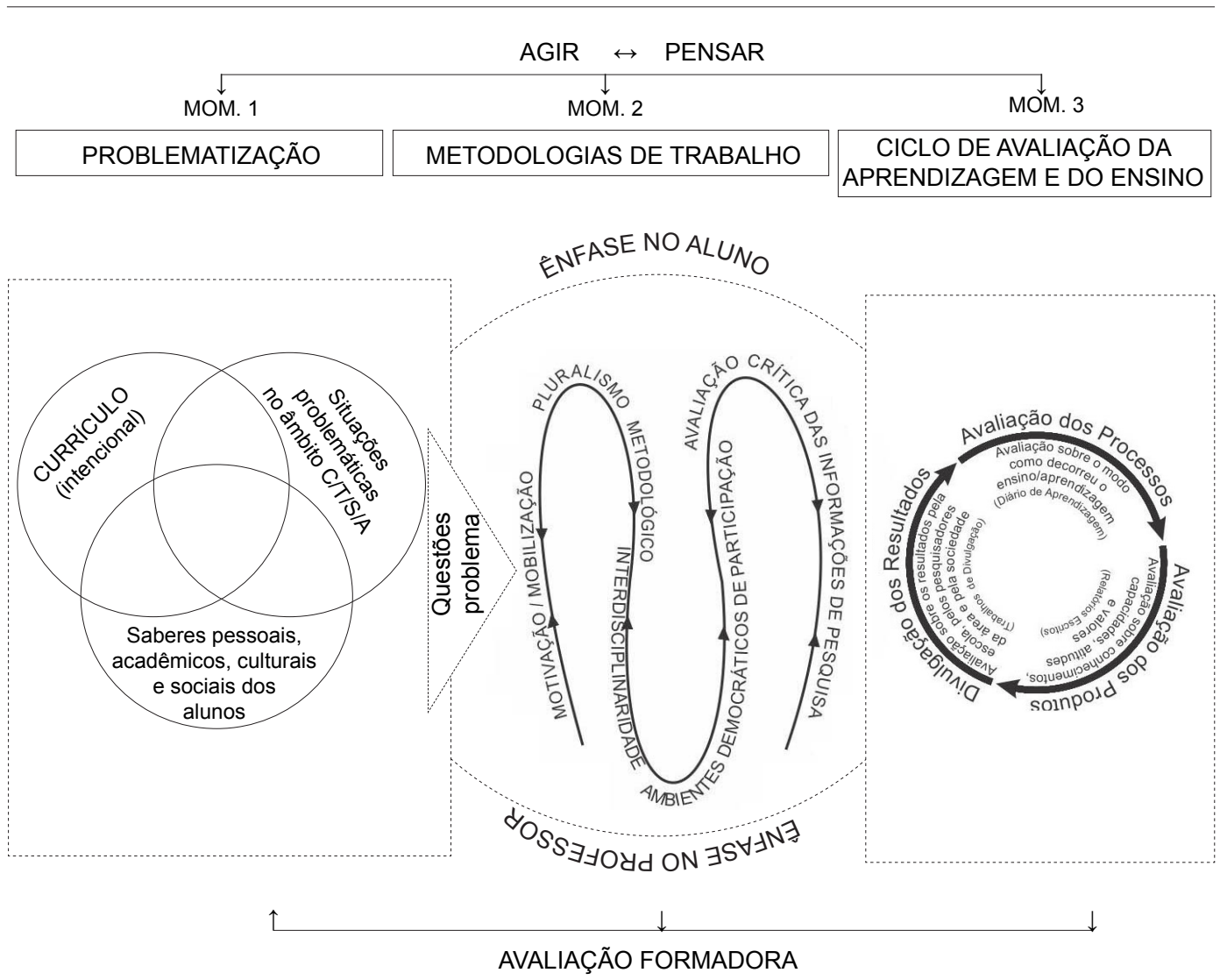

Fonte: elaborada pelos autores.

A motivação/mobilização mostrou-se necessária, pois possibilita um maior envolvimento dos alunos com o próprio processo de ensino e aprendizagem. A reinterpretação da "equação de Vroom" - “(Motivação $\leftrightarrow$ Mobilização) = Expectativa $\mathbf{x}$ Valor" - permitiu evidenciar que estratégias de ensino articuladas no EPP de Núcleos Integrados devem gerar expectativas nos alunos como forma de se obter uma motivação imediata em seus estudos. À medida que são aprofundadas as discussões e as pesquisas sobre o problema estudado e debatido, deve-se agregar, desenvolver, questionar e (re)construir valores para que a motivação inicial se configure em uma efetiva mobilização dos alunos pelo seu processo de ensino e aprendizagem. 
O pluralismo metodológico deve ser estimulado tanto por parte dos professores quanto por parte dos alunos, devido às importantes contribuições para o ensino de ciências. Conforme destacam Laburu, Arruda e Nardi (2003), a utilização de estratégias de ensino plurimetodológicas por parte dos professores possibilita promover um processo de ensino e aprendizagem acessível aos mais diferentes tipos de alunos, provenientes das mais variadas realidades sociais. Por sua vez, estímulo aos alunos para a iniciativa de realizar suas pesquisas por meio de metodologias plurais permite o levantamento de informações por diferentes fontes, a comparação de informações e dados distintos, o que possibilita um questionamento crítico sobre os temas de pesquisa, além de estimular a atividade investigadora de buscar informação para compreender o mundo que os cerca e as problemáticas nele existentes.

O estabelecimento de ambientes democráticos de participação consiste em um importante elemento de ensino e aprendizagem presente no EPP de Núcleos Integrados, e é essencial para a formação de cidadãos cientificamente cultos, pois possibilita momentos em que os alunos têm a oportunidade de expressar suas ideias e opiniões e, sobretudo, respeitar o direito dos demais alunos em expressar suas opiniões, mesmo elas sendo conflitantes ou divergentes, fomentando o diálogo orientado à tomada de decisões de forma coletiva. Assim, são cultivados valores democráticos e humanos essenciais para a convivência em sociedade.

Avaliação crítica das informações de pesquisa no EPP de Núcleos Integrados resulta do estímulo dado pelo professor aos alunos para manterem um questionamento crítico permanente acerca de suas fontes de pesquisa e de dados obtidos, e das informações apresentadas e sustentadas por seus colegas de grupo e de turma, tornando-se uma ferramenta fundamental para a reconstrução e apropriação do conhecimento. Em uma sociedade onde as relações de poder são estabelecidas e perpetuadas por meio da comunicação e da informação comunicada (BOURDIEU, 1997; FOUCAULT, 2010), torna-se extremamente pertinente e relevante o questionamento crítico sobre os meios de comunicação e as informações veiculadas, para que os cidadãos das sociedades pós-modernas possam tomar as decisões mais adequadas sobre as problemáticas sociocientíficas.

Acrescenta-se aqui a interdisciplinaridade que, apesar de ter sido explorada de forma superficial durante a intervenção, trata-se de um importante elemento do EPP de Núcleos Integrados, e que deve ser valorizada e melhor abordada. Ela surge da necessidade de se trabalharem e compreenderem problemáticas reais, de maior impacto social e pessoal para a vida dos alunos, em sua totalidade, promovendo apreensões mais significativas e completas. Evitamse, assim, reducionismos, análises simplistas que geram, consequentemente, um entendimento superficial e incompleto da realidade, bem como a especialização excessiva, na qual se sabe de quase nada e, portanto, não corresponde de maneira adequada às problemáticas da realidade social e seus desafios (DEMO, 2001).

Quanto ao terceiro momento do EPP de Núcleos Integrados, que diz respeito à avaliação do desempenho dos alunos ao longo das atividades de ensino e aprendizagem, esta foi realizada considerando-se os dois aspectos explícitos pela fundamentação teórica: a Avaliação dos Produtos e a Avaliação dos Processos; dentro do contexto de uma Avaliação Formadora, que não se reduziu a um único lugar ou momento, mas que foi realizada durante todo o processo. Durante a Avaliação dos Processos, ferramentas que se mostraram bastante úteis foram os Diários de Aprendizagem dos alunos. Logo, o comportamento dos alunos, a forma com que se relacionaram com seus grupos e com seus temas de pesquisa, e o modo como foram se (re)construindo 
atitudes, capacidades e valores. Além da avaliação do relatório escrito como trabalho final de pesquisa, destaca-se, durante a Avaliação dos Produtos, a avaliação realizada pelos próprios alunos durante o debate, de caráter muito mais formador e crítico do que as tradicionais avaliações classificatórias e momentâneas.

Acrescenta-se aqui, durante o momento avaliativo, uma etapa destinada à Divulgação dos Resultados obtidos com as estratégias de ensino e aprendizagem. O principal objetivo em acrescentar esta etapa é a de permitir uma apreciação e avaliação da prática discente e docente pela comunidade escolar, pela comunidade de pesquisadores da área de Ensino de Ciências, e pela sociedade em geral. A divulgação no meio escolar visa trazer à tona as necessidades provenientes desse ambiente e dos alunos e professores de ciências que nele atuam, bem como possibilitar um diálogo com suas reflexões e contribuições para as teorias de ensino e aprendizagem. Sugere-se, aqui, a apresentação dos resultados de pesquisa de todos os grupos para a comunidade escolar, algo que não foi possível na intervenção aqui analisada, e configura-se, portanto como uma meta a ser atingida no processo de ensino e aprendizagem. Ainda em relação à divulgação, para a comunidade escolar, do presente texto, mesmo antes de ser publicado, este foi entregue à direção da escola e enviado via e-mail aos alunos que participaram da intervenção. Tal avaliação é algo que já ocorre quando se realiza a divulgação para a comunidade de pesquisadores do ensino de ciências, onde estes, consequentemente, contribuem para que ocorram avanços na área.

Por sua vez, a divulgação dos resultados das práticas docentes para a sociedade em geral converge diretamente com um dos principais objetivos do ensino em CTSA, que consiste em trazer, à sociedade, debates democráticos de avaliação da atividade científica e tecnológica. Logo, a concretização de tal objetivo perpassa pela apreciação e avaliação das práticas de ensino em ciências empregadas nas escolas pelas diversas instâncias da sociedade.

No modelo proposto por Cahapuz, Praia e Jorge (2002), o terceiro momento, Avaliação Terminal da Aprendizagem e do Ensino, as avaliações parecem estar hierarquizadas e isoladas, assim como os polos de interação presentes no primeiro momento, problematização. No modelo aqui proposto, as várias instâncias das avaliações estão interligadas entre si e são igualmente importantes, o que, por sua vez, sinaliza a influência mútua entre elas. Assim, o processo de avaliação aqui proposto inicia-se na Avaliação dos Processos, que, por sua vez, auxilia e avança para a Avaliação dos Produtos e, posteriormente, avança para a Divulgação dos Resultados, que é, em si, uma retomada à avaliação tanto dos processos quanto dos produtos (conforme ilustrado na Figura 3). Logo, configura-se, no terceiro momento do EPP de Núcleos Integrados, o que aqui é denominado de Ciclo de Avaliação da Aprendizagem e do Ensino.

Enfim, são (re)caracterizados os momentos pedagógicos da proposta do Ensino por Pesquisa. Momentos esses que não se completam em uma sequência linearmente rígida e definida. Pelo contrário, o EPP de Núcleos Integrados representa uma proposta dinâmica, em que o movimento constante entre os momentos, desenvolvidos conjuntamente por professor(es) e aluno(s), possibilita um ensino igualmente dinâmico, capaz de se adaptar a situações novas e ao possível surgimento de problemas inesperados. É preciso ter em mente, ainda, que o EPP de Núcleos Integrados não é um roteiro mecânico ou uma receita de um método infalível de ensino e aprendizagem. Estando em consonância com os argumentos do construtivismo em educação em ciências (GIL-PÉREZ et al., 2011), o EPP de Núcleos Integrados consiste em um conjunto de saberes e conhecimentos que se deve ter em conta ao se trabalhar a pesquisa como atividade didática de ensino e aprendizagem. 


\section{$\overline{\text { Referências }}$}

ACEVEDO DÍAZ, J. A.; VÁZQUEZ ALONSO, A.; MANASSERO MAS, M. A. Papel de la educación CTS en una alfabetización científica y tecnológica para todas las personas. Revista Electrónica de Enseñanza de las Ciencias, Vigo, v. 2, n. 2, p. 80-111, 2003. Disponível em: <http://reec.uvigo.es/volumenes/volumen2/REEC_2_2_1.pdf>. Acesso em: 06 jan. 2015.

AIKENHEAD, G. The integration of STS into science education. Theory into Practice, Philadelphia, v. 31, n. 1, p. 27-35, 1992.

AIKENHEAD, G. S. Consequences to learning science through STS: research perspective. In: SOLOMON, J.; AIKENHEAD, G. S. (Org.). STS education: international perspectives on reform. New York: Teachers College Press, 1994. p.169-186.

AIKENHEAD, G. S. Teaching science through a science-technology-societyenvironment approach: an instruction guide. Regina: University of Regina: Saskatchewan Instructional Development \& Research Unit, 1988. (SIDRU Research report, 12).

BAUMAN, Z. Vida para consumo. Rio de Janeiro: Zahar, 2008.

BAZZO, W. A.; LINSINGEN, I. V.; PEREIRA, L. T. V. (Ed.). Introdução aos estudos CTS (Ciência, Tecnologia e Sociedade). Madrid: Organização dos Estados IberoAmericanos para a Educação, a Ciência e a Cultura, 2003. (Cadernos de Ibero-América).

BOGDAN, R.; BIKLEN, S. Investigação qualitativa em educação. Porto: Porto, 1994.

BOURDIEU, P. Sobre a televisão. Rio de Janeiro: Jorge Zahar, 1997.

BRASIL. Ministério da Educação. Parâmetros curriculares nacionais: ensino médio. Brasília: Secretaria de Educação Média e Tecnológica, 1999.

CACHAPUZ, A.; PRAIA, J.; JORGE, M. Ciência, educação em ciência e ensino de ciências. Lisboa: Ministério da Educação, 2002.

. Da educação em ciência às orientações para o ensino das ciências: um repensar epistemológico. Ciência \& Educação, Bauru, v. 10, n. 3, p. 363-381, 2004. Disponível em: <http://dx.doi.org/10.1590/S1516-73132004000300005 >. Acesso em: 06 jan. 2015.

COLLINS, H.; PINCH, T. O Golem: o que você deveria saber sobre ciência. Belo Horizonte: Fabrefactum, 2010.

CORTELLA, M. S. A escola e o conhecimento: fundamentos epistemológicos e políticos. São Paulo: Cortez, 2011.

DEBOER, G. E. A history of ideas in science education: implications for practice. New York: Teachers College, 1991.

DEMO, P. Saber pensar. São Paulo: Cortez, 2001.

FOUCAULT, M. A ordem do discurso. São Paulo: Loyola, 2010. 
FOUREZ, G. Crise no ensino de ciências? Investigações em Ensino de Ciências, Porto Alegre, v. 8, n. 2, p. 109-123, 2003.

GENOVEZ, L. G. R. Diário de aprendizagem no ensino de física: construção, categorização e considerações. In: SIMPÓSIO NACIONAL DE ENSINO DE FÍSICA, 16., 2005, Rio de Janeiro. Anais... Disponível em: < http://www.sbf1.sbfisica.org.br/eventos/snef/xvi/cd/ resumos/T0372-1.pdf>. Acesso em: 06 jan. 2015.

GIL-PÉREZ, D.; CARRASCOSA-ALIS, J. Bringing pupils' learning closer to a scientific construction of knowledge: a permanent feature in innovations in science teaching. Science Education, Hoboken, v. 78, n. 3, p. 301-315, 1994.

GIL-PÉREZ, D.; VILCHES, A. Importância da educação científica na sociedade actual. In: CACHAPUZ, A. et al. (Org.). A necessária renovação do ensino de ciências. São Paulo: Cortez, 2011. p. 17-32.

GIL-PÉREZ, D. et al. Defesa do construtivismo: que entendemos por posições construtivistas na educação em ciências? In: CACHAPUZ, A. et al. (Org.). A necessária renovação do ensino de ciências. São Paulo: Cortez, 2011. p. 109-126.

. Para uma imagem não deformada do trabalho científico. Ciência \& Educação, Bauru, v. 7, n. 2, p. 125-153, 2001. Disponível em: <http://dx.doi.org/10.1590/S1516$73132001000200001>$. Acesso em: 06 jan. 2015.

GÓMEZ, G. R.; FLORES, G.; JIMENEZ, J. Y. G. Metodología de la investigación cualitativa. Granada: Aljibe, 1999.

GORDILLO, M. M.; OSORIO, C. Educar para participar en ciencia y tecnología: un proyecto para la difusión de la cultura científica. Revista Iberoamericana de Educación, Madrid, n. 32, p. 165-210, 2003.

GRANGER, G. G. A ciência e as ciências. São Paulo: Edit. UNESP, 1994.

HABERMAS, J. Técnica e ciência como “ideologia”. Lisboa: Edições 70, 2011.

INTERNATIONAL ATOMIC ENERGY AGENCY. The radiological accident in

Goiânia. Vienna, 1988. Disponível em: <http://www-pub.iaea.org/mtcd/publications/pdf/ pub815_web.pdf >. Acesso em: 06 jan. 2015.

LABURU, C. E.; ARRUDA, S. M.; NARDI, R. Pluralismo metodológico no ensino de ciências. Ciência \& Educação, Bauru, v. 9, n. 2, p. 247-260, 2003. Disponível em: < http:// dx.doi.org/10.1590/S1516-73132003000200007>. Acesso em: 06 jan. 2015.

LATOUR, B. Ciência em ação. São Paulo: Edit. UNESP, 2011.

PENICK, J. E. Ensinando “alfabetização científica”. Educar em Revista, Curitiba, v. 14, p. 91-113, 1998.

POZO, J. I.; CRESPO, M. A. G. A aprendizagem e o ensino de ciências: do conhecimento cotidiano ao conhecimento científico. Porto Alegre: Artmed, 2009. 
PRAIA, J.; CACHAPUZ, A. Ciência-tecnologia-sociedade: um compromisso ético. Revista Iberoamericana de Ciencia Tecnología y Sociedad, Buenos Aires, v. 2, n. 6, p. 173-194, 2005. Disponível em: <http://www.scielo.org.ar/pdf/cts/v2n6/v2n6a10.pdf>. Acesso em: 06 jan. 2015.

SANTOS, W. L. P. Contextualização no ensino de ciências por meio de temas CTS em uma perspectiva crítica. Ciência \& Ensino, Piracicaba, v. 1, 2007. (Número especial). Disponível em: <http://prc.ifsp.edu.br/ojs/index.php/cienciaeensino/article/view/149/120>. Acesso em: 06 jan. 2015.

SANTOS, W. L. P.; MORTIMER, E. F. Uma análise de pressupostos teóricos da abordagem CTS (Ciência-Tecnologia-Sociedade) no contexto da educação brasileira. Ensaio: Pesquisa em Educação em Ciências, Belo Horizonte, v. 2, n. 2, p. 1-23, 2002.

SANTOS, W. L. P.; SCHNETZLER, R. P. Educação em química: compromisso com a cidadania. Ijuí: Unijuí, 2010.

SOLOMON, J. Teaching science, technology and society. Buckingham: Open University Press, 1994.

WAKS, L. J. Filosofía de la educación en CTS. Ciclo de responsabilidad y trabajo comunitario. In: ALONSO, A.; AYESTARÁN, I.; URSÚA, N. Para comprender ciencia, tecnología y sociedad. Estella: Verbo Divino, 1996. p. 19-33.

. The responsibility spiral: a curriculum framework for STS education. Theory into Practice, Philadelphia, v. 31, n. 1, p. 13-19, 1992.

YAGER, R. Science/tecnology/society as reform in science education. Albany: State University of New York Press, 1996.

ZEIDLER, D. L. et al. Beyond STS: a research based framework for socioscientific issues education. Science Education, Hoboken, v. 89, n. 3, p. 357-377, 2005. Disponível em: <http://onlinelibrary.wiley.com/doi/10.1002/sce.20048/abstract>. Acesso em: 06 jan. 2015. ZIMAN, J. Teaching and learning about science and society. Cambridge: Cambridge University Press, 1980. 
